\title{
A Literature Review of Diesel Engine Noise with Emphasis on Piston Slap
}

\author{
Samir N.Y. Gerges ${ }^{\dagger}$ \\ Federal University of Santa Catarina, Mechanical Engineering Department, Noise and Vibration Laboratory, Cx.P. 476, \\ 88040-900, FlorianCpolis, SC, Brazil
}

Julio Cesar de Luca

Eaton Limited, Rua Clark, 2061, 13279-400, Valinhos, SP, Brazil

\author{
Nicholas Lalor \\ Institute of Sound and Vibration Research (ISVR), Southampton University, Soton S09 5NH Southampton, UK
}

(Received 20 September 1999; accepted 3 January 2000)

\begin{abstract}
The major sources of noise pollution, especially in urban areas are caused by traffic noise generated by internal combustion engines (ICE) and related systems..$^{1-3}$ Much work has already been carried out on ICE noise and piston slap, trying to answer the questions: how to measure it?, how to separate it from other excitation sources?, how does it affect the engine's operation and total radiated noise?, etc. Piston slap is still an important mechanical excitation source and a noise generator in ICE. This literature review presents a synthesis of the main technical contributions already published about ICE noise and piston slap assessment and also the important influence of the oil film on this impact phenomenon. More than seventy references, including papers, theses, dissertations and books were studied for this purpose. The following presents the summary of this review.
\end{abstract}

${ }^{\dagger}$ Member of the International Institute of Acoustics and Vibration (IIAV)

\section{INTRODUCTION}

The noise radiated from an ICE is ultimately caused by its external surface vibration, which is excited by internal sources. These vibrations excite the ICE boundary surface and radiate noise into the air.

To control ICE noise, generated by mechanical impacts, it is important to understand the behaviour and to have accurate measurements of piston slap.

Since piston slap is generated by a complex mechanism, which involves many factors. Taking into account that the noise and vibration generated in an ICE are the sums of many different sources, it is important to know and understand the possible techniques available for separating and measuring these.

This review is presented as follows: a review with the definition of the main ICE vibration and noise sources, and the principal methodologies used for their determination and the most common assessment techniques for piston slap. ${ }^{4-28}$

\section{MAIN EXCITATION SOURCES OF NOISE AND VIBRATION IN AN ENGINE}

There are many different excitation sources of vibration inside an internal combustion engine. These can be divided into two basic types: 1) those due to combustion and 2) those due to mechanical impacts (Fig. 1). For diesel engines with low cyclic torque fuel systems, combustion and piston slap $^{\text {4-16,24-28 }}$ are the main contributors to ICE vibration and noise. The predominant noise sources in most modern diesel engines are gear train rattle and impacts, which are driven by crankshaft and fuel system torsional vibration. ${ }^{29-36}$

\subsection{Noise Induced by Combustion}

These excitations are caused by the pressure of the gas mixture and the combustion process. The contribution of the combustion excitation to the noise radiated is due to the high frequency components of the pressure spectrum..$^{25-27,37-39}$ The shape of this spectrum depends basically on the type of combustion system and its parameters. ${ }^{37-39}$

The combustion system determines the rate of increase of noise with engine speed. At high engine speeds, the combustion spectrum becomes irrelevant ${ }^{11,37}$ because, for different combustion systems, the speed/noise curves converge to the same noise level when the speed increases. By normalisation of the pressure spectrum it is possible to compare the spectra for different speeds and combustion systems, such as: 1) Direct Injection, 2) Indirect Injection, 3) Turbocharged, and 4) Naturally Aspirated, Two- and Four-Stroke Engines.

The combustion noise contribution depends also on the relation between the maximum pressure in the chamber and the first and second time derivatives of the pressure. ${ }^{38}$

Generally, there are three basic ways for diesel engine combustion noise reduction: ${ }^{26}$

1) Reducing ignition delay period:

a) retarded timing;

b) high compression ratio;

c) turbo-charging;

d) heated intake air.

2) Reducing the combustion injection in the ignition delay period by controlling the initial rate of injection. 